\title{
Economics
}

\section{Research on Beijing-Tianjin-Hebei Information Platform of Logistics Industry Association Function and Construction}

\author{
Liu Shaohua, Ma Yinbo, Li Weipeng, Wan Xiaofan
}

School of Information, Beijing Wuzi University, Beijing, China

Email address:

Liushaohua2016@qq.com (Liu Shaohua),yinbo1991@qq.com (Ma Yinbo),417003857@qq.com (Li Weipeng), sunnyday1010@163.com (Wang Xiaofan)

\section{To cite this article:}

Liu Shaohua, Ma Yinbo, Li Weipeng, Wan Xiaofan. Research on Beijing-Tianjin-Hebei Information Platform of Logistics Industry Association Function and Construction. Economics. Vol. 5, No. 2, 2016, pp. 20-26. doi: 10.11648/j.eco.20160502.12

Received: May 9, 2016; Accepted: May 21, 2016; Published: June 4, 2016

\begin{abstract}
Logistics industry association as a bridge that crosses from the government and enterprises, plays an irreplaceable role. Logistics industry association information platform is the main way to spread information to logistics enterprises. If the information platform construction is insufficient or the function of platform to play is not perfect, will cause great impact to the development of logistics enterprise. In Beijing-Tianjin-Hebei are summarized on the basis of logistics industry association information platform construction, this paper expounds the function of Beijing-Tianjin-Hebei information platform of logistics industry association in detail, and lists the function of information platform of the Council of Supply Chain Management Professionals (CSCMP), by comparing with the logistics industry association abroad found that lack of information platform construction of Beijing-Tianjin-Hebei region logistics industry association. At the end of the paper puts forward several suggestions to strengthen the information construction of logistics industry association.
\end{abstract}

Keywords: Information Platform, Logistics Industry Association, Beijing-Tianjin-Hebei Function

\section{Introduction}

China's logistics industry started relatively late and all aspects of the development is not perfect, especially for a lot of problems in the construction of the logistics industry association. Under the situation of integration of the Beijing-Tianjin-Hebei region, the study of Beijing-Tianjin-Hebei logistics industry association information platform has very important significance.

Industry association in our country is developing with the establishment and perfection of the market economy system. [1] It is the product of the economic system reform and economic development. Under the condition of market economy, especially in the construction period of the socialist market economy with Chinese characteristics, the role of industry association have been looking for the people all the time. Relevant experts pointed out: the logistics industry associations should be with support from the government and enterprise, adhere to the service of the fundamental purpose, to carry out some of the government and the industrial enterprises are not easy to carry out work, such as personnel training, business consulting, information services, industry self-discipline, opinions and Suggestions for the decision of the government, etc., play bridge and the link role. [2] The domestic scholars have little research on the logistics industry association. Lu Ze was studied the modern logistics in Hebei province association and he also put forward several construction measures. [3] Xue Junlin discussed the measures to improve the logistics industry development in the perspective of the industry association social service mechanism. [4] Wang Qiuling analyzed the problems and deficiencies of the logistics industry association, and put forward the countermeasures to promote the development of logistics enterprises. [5] Huang Shuxian summarized the development and service supply conditions of logistics industry association of Guangdong province. [6]

Logistics industry association information platform is mainly through the establishment of Internet sites to provide information platform for the industry. Through the channel such as professional books and websites to collect domestic and foreign logistics information, laws and regulations, information papers and professional books, sorting and analyzing the data of the logistics industry development for 
the enterprise development and expansion provides comprehensive and personalized information service.

Integration of the Beijing-Tianjin-Hebei region is development by the concept of capital economic Circle, including Beijing, Tianjin and Hebei Province of Baoding, Tangshan, Shijiazhuang, Xingtai, Handan, Hengshui, Cangzhou, Qinhuangdao, Langfang, Zhangjiakou and Chengde, involving in the Beijing and Tianjin and 11 cities in Hebei province. Through statistics, there are 92 logistics industry association in Beijing-Tianjin-Hebei region, the information platform construction is not perfect, and in terms of each region, the information platform construction condition is uneven. Through the analysis of other relevant article, I find a lot of defects about the research of the logistics industry association information platform construction in China. One, the related research is less. Second, the study is not specific enough. Especially, there is almost no research about the Beijing-Tianjin-Hebei logistics industry association. The purpose of the paper is the study of Beijing-Tianjin-Hebei logistics industry association information platform function condition. And later I summarized the function of the logistics industry association information platform. The function of the information platform of logistics industry association according to development status is also different. By comparing with the function of information platform of the Council of Supply Chain Management Professionals (CSCMP) found that lack of information platform construction of Beijing-Tianjin-Hebei region logistics industry association. At the end of the paper puts forward several suggestions to strengthen the information construction of logistics industry association. The purpose is to make Beijing-Tianjin-Hebei logistics industry association information platform to be improved, and it can better service to government and enterprise.

\section{The Introduction to Function of Information Platform of Beijing-Tianjin-Hebei Logistics Industry Association}

Statistical analysis of the function of Beijing-Tianjin-Hebei regional association information platform, and through bar chart describes the regional association information platform to the ratio of the function, as shown in Figure 1.

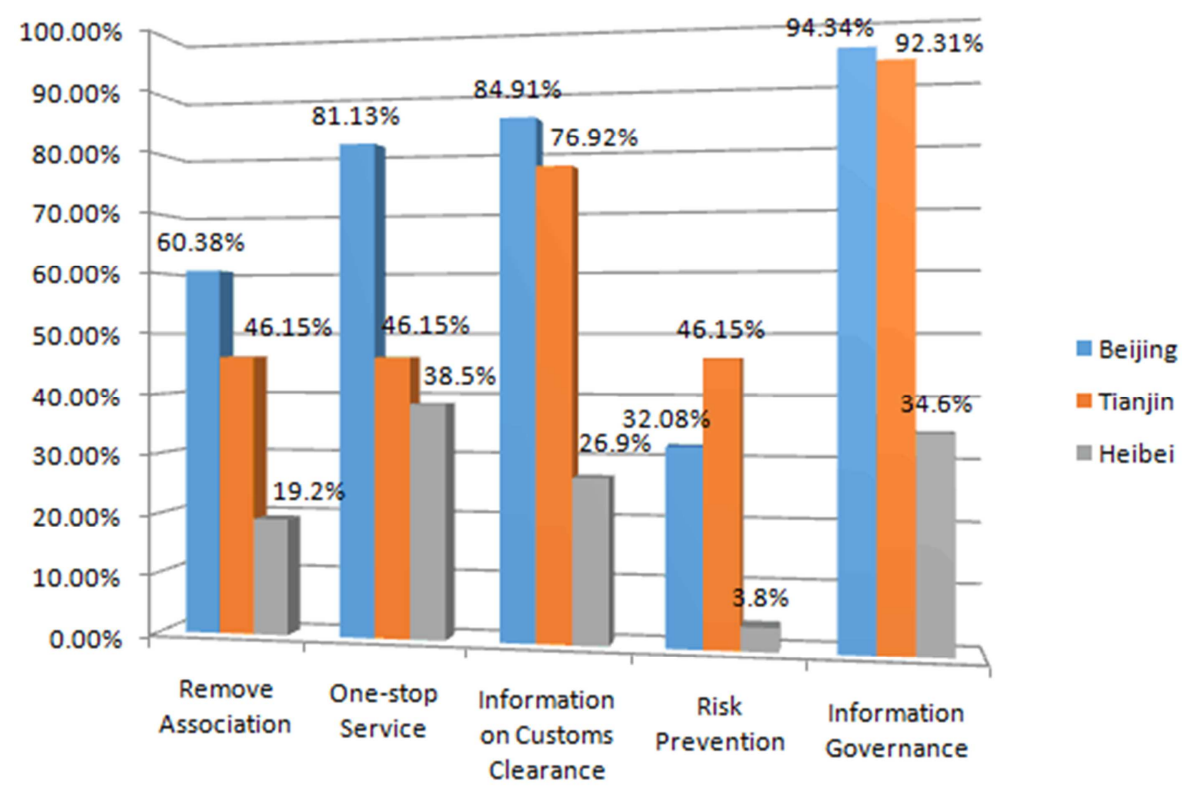

Figure 1. Beijing-Tianjin-Hebei regional logistics association information platform function ratio.

Beijing-Tianjin-Hebei logistics industry association, as a special third sector, through the application of information technology and the use of information resources, and makes the comprehensive integration of public information platform, establish and improve various types of database and network, that can and has the function of service and management of the enterprise. Beijing-Tianjin-Hebei logistics industry association as the intermediate organization plays an important role in the market economic activities in Beijing-Tianjin-Hebei, basic function is the relationship communication between companies and government, services for enterprises and the government, the function of information platform is a means to achieve the basic functions of logistics industry associations, mainly in Remove Association, One-stop Service, Information on Customs Clearance, Risk Prevention, Information Governance five aspects.

\subsection{Remove Association}

With the rapid increase of global intelligent mobile phone penetration rate and the new network connected devices, as well as the expansion of mobile broadband networks and services, remove association will undoubtedly play an important role in the future information. Beijing-Tianjin-Hebei region logistics industry association to 
build the logistics public information platform, mobile users through public information platform for information, the users don't need to buy expensive, to support information system of application server, database server, access to information and related equipment, simply by mobile communication technologies such as PDA, mobile phones and satellite communications will be able to access to information and services. At the same time, through the association of public information mobile platform, all users in accordance with a set of standard business processes, unified logistics business standards, to achieve high quality information sharing between users. For example, China's logistics combined transport association of China logistics portal, there are options available information and the function of the sources of information, as shown in Figure 2. In addition, the China Federation of Logistics \& Purchasing, China International Freight Forwarders Association and so on, have the We chat public and official Weibo platform, it also reflects the function of the mobile association.

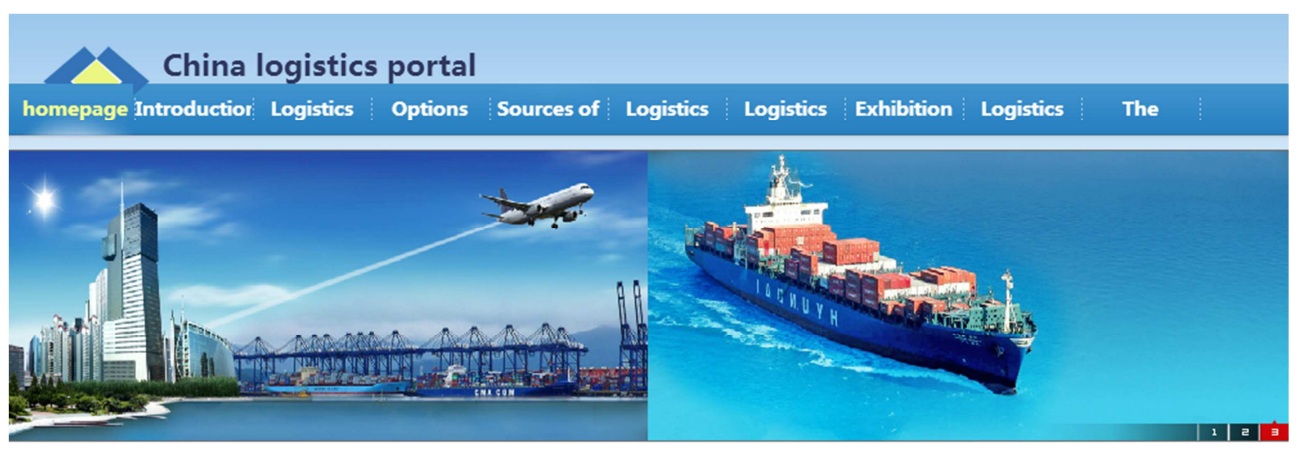

Figure 2. Chinese logistics portal.

\subsection{One-Stop Service}

Logistic industry association one-stop service platform gathers all kinds of Beijing-Tianjin-Hebei region large, medium and small logistics enterprises operating facilities and information system. Data interaction platform is responsible for the standardization and standardization of logistics information system of public information definition, acquisition, processing, organization and storage, implement the data exchange and format conversion function, to realize the cross-platform connection and interaction between different logistics information system, to promote the smooth operation of logistics system, to provide one stop service for member of logistics industry association. [7] For example, the China Federation of Logistics and Purchasing, a large size and relatively influential logistics industry association in Beijing, its information platform services are mainly enterprises bidding evaluation, information, policies and regulations, logistics, case logistics information, credit rating, standard, statistics, etc., as shown in Figure 3, give full play to communicate the relationship between enterprise and the government, service enterprise and the government.
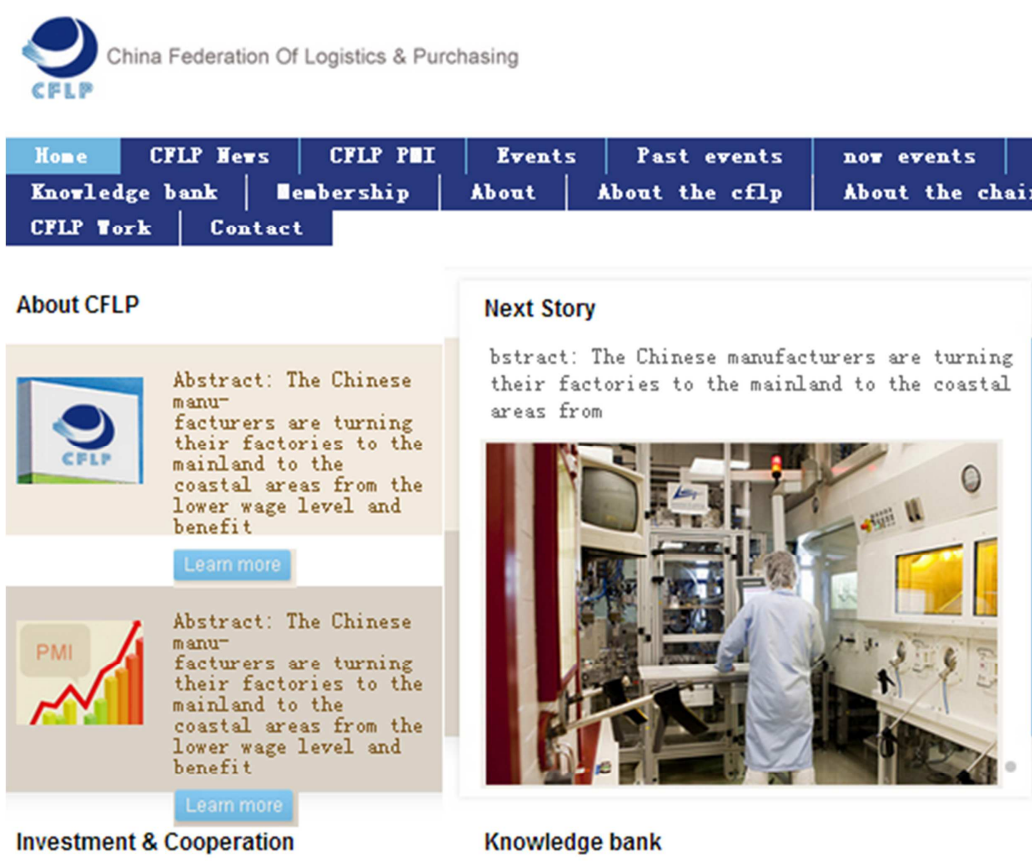

CFLP News

Figure 3. China Federation of Logistics and Purchasing information platform. 


\subsection{Information on Customs Clearance}

The smooth flow of logistics information is critical to improve the operation efficiency and operation efficiency of the logistics industry. The information service platform connects the logistics enterprise, the upstream and downstream manufacturing enterprise, the government department and so on, forms the complete supply chain system, satisfies the different logistics profession information demand and the functional demand. [8] For example, for logistics industry association member of the Beijing-Tianjin-Hebei region, provide distribution and query the logistics supply and demand, logistics cost and logistics service quality and other real-time information; For government department, it can publish industries such as information laws and regulations policy, query during a certain period of time, a certain regional range, even is historical statistical data within the scope of certain functions reflect the logistics industry activities and analysis logistics development trends, to assist the government macroscopic policy decision. For example, the Tianjin International Freight Forwarders Association information platform has played a very important role, as shown in Figure 4.

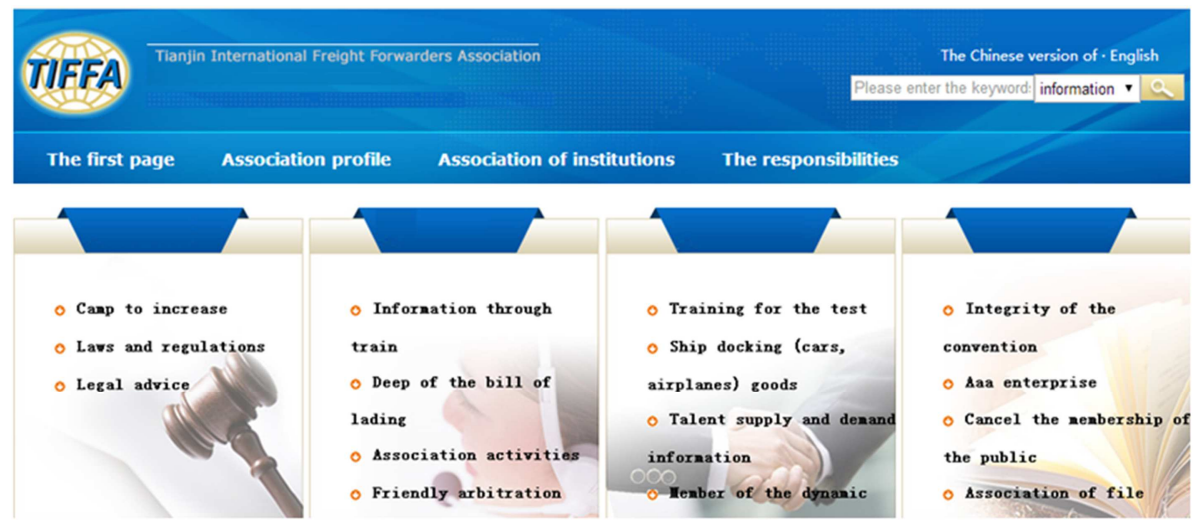

Figure 4. Tianjin International Freight Forwarders Association information platform.

\subsection{Risk Prevention}

From the logistics industry association member angle, the logistics industry association as a kind of third sector organizations can largely reduce the industry association in contract signing and implementation of the transaction cost. Logistics industry association through the establishment of the logistics industry enterprise transaction information database to provide information about the history of enterprise information records, reduce information asymmetry and the risk of cooperation between members. [9] From the social point of view, the transaction cost is needed to obtain accurate market information, logistics industry association engaged in historical trading information services, and far less than the enterprise search information costs alone. It plays a scale economic benefit. From a risk point of view, through the establishment of credit rating, credit certification for enterprises, can improve the membership of enterprises and thus control the risk. For example, the China Medical Pharmaceutical Materials Association information platform has credit evaluation, as shown in Figure 5.
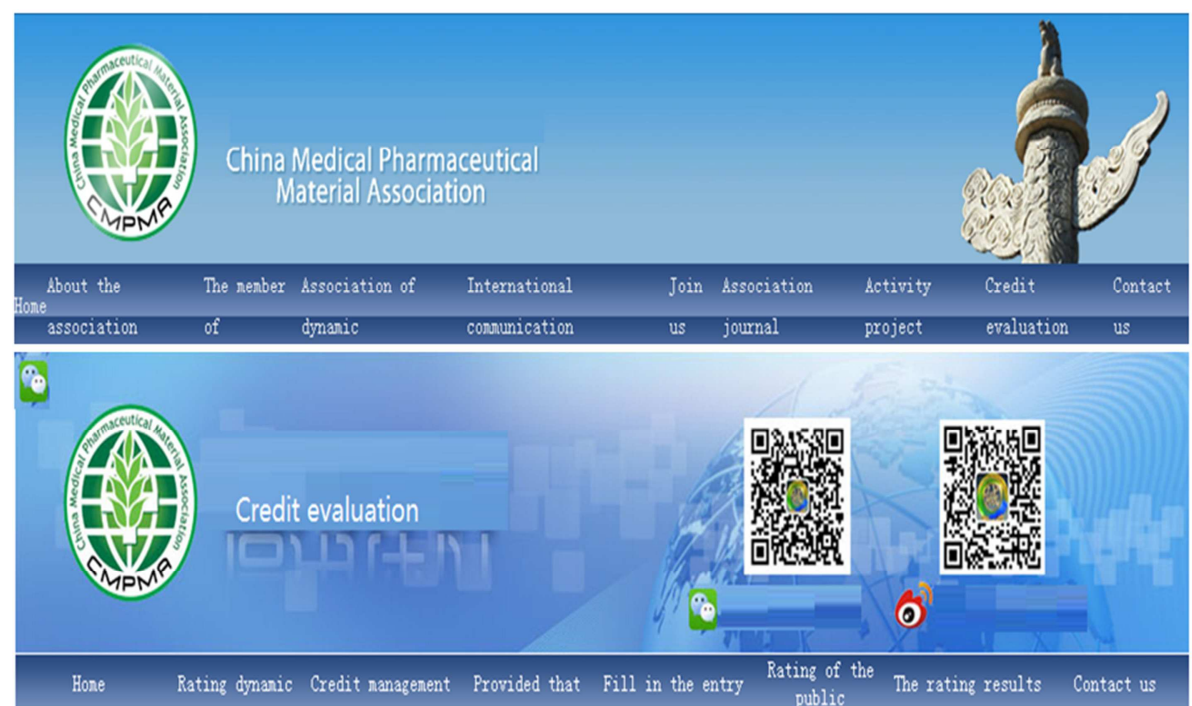

Figure 5. China Medical Pharmaceutical Materials Association information platform. 


\subsection{Information Governance}

For logistics industry association, effective supervision and management not only need third departments of self-discipline, but also requires extensive participation of the government and the community. [10] To construct a perfect mechanism of Industry Association of supervision and management, logistics industry associations to adapt the requirement of information, construction convenient for the public to participate in the information supervision system, supervision of various types of feedback information published on the Association website, comprehensive use of the integrity of the regulatory and other means, according to the law in accordance with the regulations of the public found problems, timely and comprehensive to play a supervisory role in promoting, and ultimately the formation of logistics industry association self-discipline and government, social heteronomy, benign interaction between the situation. In Beijing-Tianjin-Hebei 92 logistics industry association, there are 71 industry association information platform construction of the information supervision and feedback links, effectively promoted the government, enterprises, social interaction, improves the ability of information management. For example, the Hebei Province Association of Modern Logistics has a network supervision zone, as shown in Figure 6.

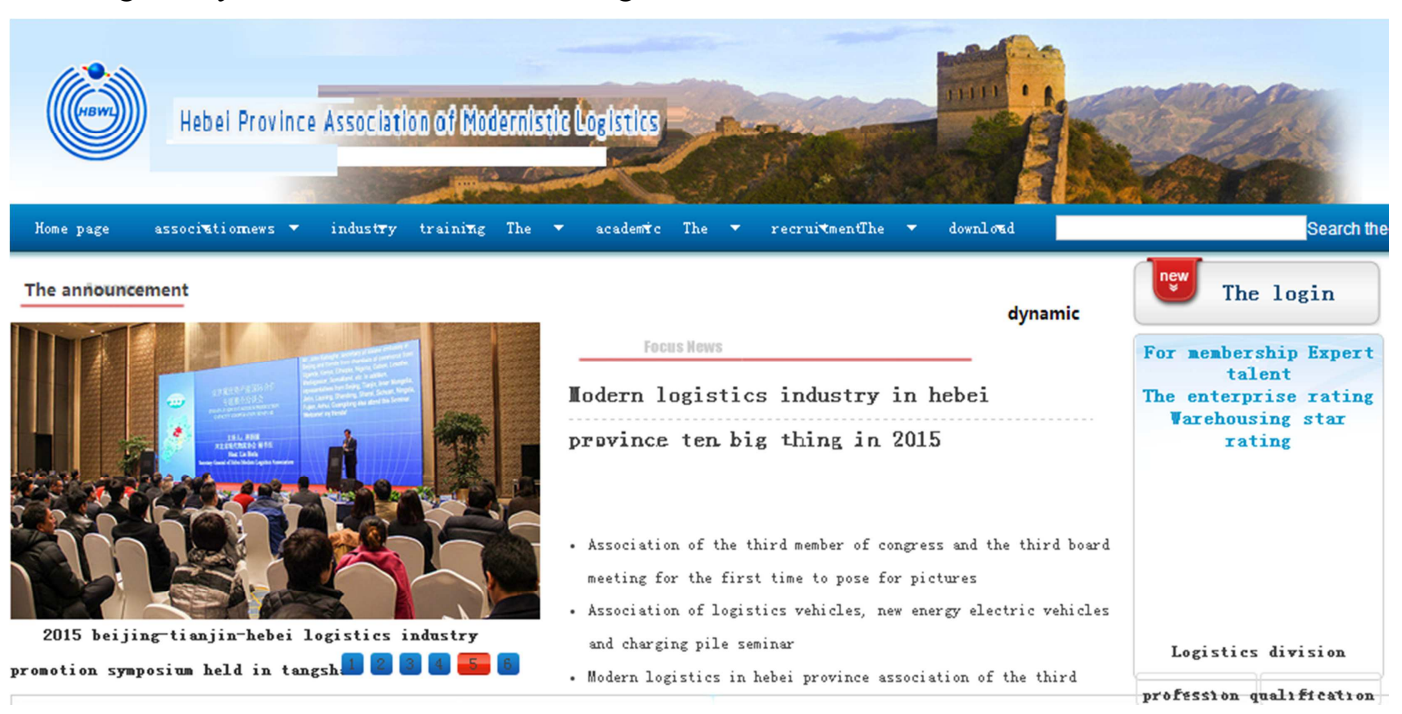

Figure 6. Hebei Province Association of Modern Logistics information platform.

\section{The Foreign Information Platform Construction Situation of Logistics Industry Association}

Foreign logistics industry association is a bridge that crosses from the government and enterprises. Such as Japan Institute of Logistics Systems (JILS) is composed together by the government, enterprise and academia, not only have the functions of academic research, also under the government guidance and the authorization to participate in logistics management. Japan's "comprehensive logistics implementation strategy outline" and "the new integrated logistics implementation strategy outline" of the early industry research and policy research, is borne by the Japan association of logistics system and the Japanese electrical association, its specific implement and promote the work, is mainly organized and implemented by the industry association. The United States as early as 1963, established the National Council Physical Distribution Management (NCPDM), in 1985 changed its name to the Council Logistics Management (CLM), later renamed the Council of Supply Chain Management Professionals (CSCMP), in addition to the logistics management and technology research and the exchange, it also assist the government in the management of the logistics industry.

The United States Council of Supply Chain Management Professionals (CSCMP), founded in 1963, is the world's outstanding professional associations, committed to the supply chain management research. [11] Has more than 8500 members from 67 countries. These members represent almost all of the industry, government and academia. CSCMP information platform construction is mainly manifested in its official website and some knowledge on logistics and supply chain management magazine in promotion and propaganda. The information platform of CSCMP is shown in Figure 7.

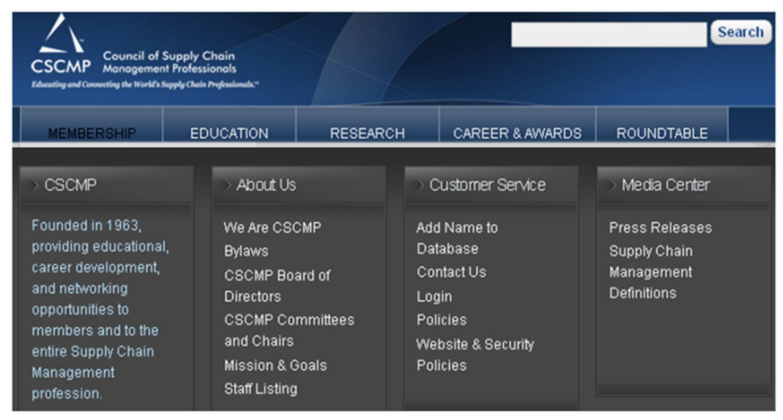

Figure 7. Council of Supply Chain Management Professionals information platform. 
The American association of Council of Supply Chain Management Professionals information platform consists of the following six aspects of content.

First, it introduces the nature of the Council of Supply Chain Management Professionals, and what aspects study it devote to, including what part of its components, as well as the various parts of the function.

Second, the platform has the association's management system and the introduction of a number of relevant provisions.

Third, the web site will be published from the world's various countries and the logistics of the field of experts, researchers and scholars, as well as their work in the association and the work of the position.

Fourth, the association as a bridge between government and enterprise, will put the latest relevant policy of the government, in the form of text and report released to the web site, for such enterprises can quickly and convenient to view this information, to make corresponding consolidation adjustment measures. In addition to release information about the policy, the association will also release some important information, such as annual global conference that the once posted to the website, the information of supply chain professionals from around the world, you'll get the roundtable information, in order to communicate and share knowledge.

Fifth, for lovers of supply chain, the website plays a very important role. [12] Association will collect some related professional counseling information, the more and broader supply chain knowledge posted to the website, convenient people cognitive and learning; It also published some dynamic enterprise, including the development of new technologies, the introduction, etc.

Sixth, to stand in the Angle of the scholars, the association website, will provide a lot of online resources, communicate and share knowledge, continuing education and professional examination and approval, qualification authentication, online learning, it will cultivate a large number of professional talents for the enterprise, to provide and promote the quality of the network members the opportunity to benefit.

Therefore, comprehensive point of view, the Council of Supply Chain Management Professionals (CSCMP) official website platform is a high quality source of information, the platform of logistics information collection, transmission, storage, processing, output, etc., have become important decision basis, on the whole logistics activity command, coordination, support and guarantee, communication, guidance and coordination, the role of management control. It has high openness. At the same time, it tends to be diversified in the service area, and it also improves the information interaction in a wider range.

In addition, CSCMP will regularly publish some magazines and newspapers, content mostly in the form of association, some results on the development of the exhibition, conference, the supply chain management professional knowledge and some important relevant dynamic. It is very important for people to understand the association and to join the member. It also can make up for the deficiency of the website information aspects.

\section{Conclusion}

International experience shows that the more competitive areas and enterprises, the greater the role of non-governmental organizations. Therefore, the transformation of economic development stage in our country should draw lessons from foreign experience, establishing and perfecting the management authorized by industry logistics intermediary organizations, establishing provincial and city-level logistics industry organization, forming a complete logistics industry self-discipline management system, bringing industry association in the enterprise management, market regulation, self-discipline, industry standards, academic organization and coordination of the exchange of research and personnel training, etc.

At present, China Federation of Logistics \& Purchasing is one of the direct management of the ministry of commerce integrated association, some provinces and cities have also built a similar organization, but because of the compartmentalization of traditional institutional factors, it is difficult to cover logistics of this industry. We should further expand the coverage of the industry associations, promote functional integration, strengthen the organization and coordination, improve self-discipline, enhance the competitive advantage of the logistics industry management. [13] From the association of logistics information platform construction situation in our country, we also need to strengthen the building of the following aspects:

a. Through positive publicity, accelerate the association information operations. Actively planning in the process of forming their own websites, to promote information network, office automation.

b. By strengthening enterprise member information technology training, make the enterprise employees better use of information platform.

c. Integrating all kinds of favorable information resources, building a large and comprehensive database.

\section{Acknowledgements}

The study is supported by Beijing Key Laboratory of Intelligent Logistics System, (BZ0211), and the project of scientific training program for Beijing Wuzi University college students (2016103050), and Beijing Intelligent Logistics System Collaborative Innovation Center.

\section{References}

[1] Xu Jialiang. (2010) Mutual benefit organization: China industry association study [M]. Beijing: Beijing normal university press.

[2] Tan Rongzhu. (2005) Fully give play to the role of logistics association, to promote healthy development of the logistics industry $[\mathrm{J}]$. Journal of goods storage and transportation and maintenance, (6) 40-41. 
[3] Huang Shuxian. (2011) Research on the service supply of industry associations in Guangdong Province -- a case study of the logistics industry association of Guangdong province $[\mathrm{J}]$. China market, 23: 33-34.

[4] Wang Qiuling. (2015) Research on small and medium sized traffic logistics enterprises in the association of Logistics Industry Association -- Based on the practical analysis of Ningbo [J]. logistics technology, 05: 20-22.

[5] Xue Junlin. (2013) Enhanced industry association function to enhance the sustainable development of modern logistics industry in Sanming City [J]. Shandong industrial technology, 12: 196-197.

[6] Lu Ze. (2015) Modern Logistics Association of Hebei Province: Taking the evaluation of social organization as an opportunity to comprehensively promote the construction level of the association [J]. China social organization, 10: 24-25.

[7] Jiang Yanning. (2011) The current situation of the development of logistics industry association and the function promotion countermeasures study [J]. Journal of logistics technology, 34 (1): $45-47$.
[8] Chen Taiyang. (2008) The website link analysis of the domestic and foreign enterprises and network influence evaluation [J]. Journal of theory and practice of intelligence No. 17704: 614-619.

[9] Guo Wei. (2011) Government regulation and industry self-discipline $[\mathrm{M}]$. China social sciences press.

[10] Feng Yue. (2015) Perfect legal system of China's logistics industry research [J]. Journal of legal system of expo, 46-47.

[11] Berman, Jeff. (2013) CSCMP Panel Focuses on Critical Industry Regulations [J]. Journal of Supply Chain Management Review. 12(7): 74-76.

[12] Wang Lan. (2014) Logistics industry association website evaluation system research [D]. Anhui University.

[13] Ma Hongxia. (2007) The logistics industry development of China's logistics industry revelation [D]. Foreign Economic and Trade University. 